\title{
IMPACT OF GLN/GLU27 POLYMORPHISM OF B2 ADRENERGIC RECEPTOR ON BRONCHIAL ASTHMA SUSCEPTIBILITY AND DRUG RESPONSE IN CHILDREN
}

\author{
Khalid Mohamed Salah , Hadeel Mohamed Abd El-Rahman , Ahmed El-Sadek Fakhr', \\ Mohamed Ismail Marghany ${ }^{a *}$. \\ ${ }^{\text {a }}$ Pediatric Pulmonology Department, Faculty of medicine, Zagazig University, Egypt. ${ }^{\text {BScientific }}$ \\ and Medical Research Center, Faculty of medicine, Zagazig University, Egypt.
}

\begin{tabular}{l} 
ABSTRACT \\
Background: Bronchial asthma is one of the most prevailed non-communicable diseases among Egyptian \\
children and all over the world. Genetic-environmental interaction can influence the nature of many diseases \\
including asthma and considering $\beta 2$ agonists as one of the most commonly prescribed bronchodilators for \\
relieving asthma symptoms, so this study was conducted to investigate the possible relationship between \\
Gln27/Glu polymorphism of ADR $\beta 2$ from one side and bronchial asthma susceptibility, severity and \\
responsiveness to Albuterol (short-acting ADR $\beta 2$ agonist) from the other side. \\
Subjects and methods: A case control study of one hundred Egyptian children was designed. All \\
participants were genotyped using allele-specific Polymerase chain reaction (PCR) to assess single \\
nucleotide polymorphism (SNPs) of ADR $\beta 2$. Fifty asthmatics, their mean age was $(8.10 \pm 2.52)$, who were \\
selected and classified according to GINA guidelines, 2017 and spirometerically assessed to evaluate \\
pulmonary functions. Another fifty matched healthy participants were selected as a control group with a \\
mean age of (8.44 \pm 2.40$)$. \\
Results: Gln allele frequency $=0.59$ and Glu allele frequency $=0.41$ for cases with Chi- squared $\boldsymbol{X}^{2}=\mathbf{0 . 1 2}$ \\
and Gln allele frequency = 0.56 and Glu allele frequency $=0.44$ for control participants with $\boldsymbol{X}^{2}=\mathbf{0 . 9 3}$. \\
There were no statistically significant differences between patients and control regarding Gln27/Glu \\
polymorphism. Gln27 was the only genotype having positive association with both asthma severity and drug \\
response, as it represents only $17.2 \%$ of all mild cases, $56.3 \%$ of all moderate cases and about $80.0 \%$ of all \\
sever studied cases; P value $(0.003)$. \\
Conclusion: B2 adrenergic receptor polymorphism at codon 27 is not associated with asthma susceptibility; \\
however it can be a determinant factor for asthma severity and bronchodilating response to B2 agonists in \\
Egyptian asthmatic children, to be confirmed by further Pharmacogenomic studies. \\
Key words: B2 adrenergic receptor, susceptibility, asthma, polymorphism, Phenotype. \\
\hline Corresponding author: Mohamed Ismail Marghany, Email:drmohamedzahran8@gmail.com \\
Tel No. 01127025037.
\end{tabular}

\section{INTRODUCTION}

B ronchial asthma is a complex heterogeneous and multifactorial disease manifested as episodes of wheezing, coughing, and difficult breathing. Asthma is a complex polygenic disorder in which, many cells and cellular elements play a role in particular, mast cells, eosinophils, T lymphocytes, macrophages, neutrophils and epithelial cells ${ }^{[1]}$.

WHO declared that, about 235 million people are suffering from asthma ${ }^{[2]}$. The prevalence of asthma among children in Egypt is $14.7 \%$ [3], where positive family history, overcrowding and bad housing conditions are the more commonly reported risk factors ${ }^{[4]}$. The B2 adrenergic receptor, which is located on chromosome 5q31-q32 and encodes for the development of 413 amino acids, is found on the surface of smooth muscle cells of airway and plays a vital role in the reactivity of the airways to B2 agonists ${ }^{[5]}$.

Catecholamines or B2-agonists activate ADRB2 receptors in the airways, causing bronchodilatation and relief of wheezing symptoms. In airway smooth muscle cells, the $\beta 2$ agonists activate adenylyl cyclase enzyme through membrane-coupled G-proteins; this activation increases the intracellular cAMP (cyclic adenosine monophosphate) concentration leading to relaxation of smooth muscles of airway causing its dilatation. The $\beta 2$ adrenergic agonists may also affect $\mathrm{Ca}^{2+}$ and $\mathrm{K}^{+}$channels in smooth muscles and lead to relaxation independently of cAMP mechanism. Defects in this receptor might have a pathogenic role in asthma ${ }^{[6]}$.

Several single nucleotide polymorphisms (SNPs) in B2 adrenergic receptors have been discovered, Four of these result in amino acid substitutions at amino acids 16, 27, 34, and 164, while there are 5 silent ineffective mutations located at amino acids $84,175,351,366$, and $413^{[7]}$. 
Gln27Glu polymorphism $(\mathrm{C}>\mathrm{G})$ at nucleotide 79 , can cause differential agonist-stimulated down-regulation in cell systems of the B2 adrenergic receptor, affecting human airway smooth muscle cells and drug response ${ }^{[8]}$. Several previous studies have revealed possible relation between asthma and polymorphisms in the coding region of the $A D R B 2$ gene, especially Gln27Glu SNPs (single nucleotide polymorphism), where Glutamic acid is substituted for Glutamine at codon 27. But some of these studies have got conflicting results ${ }^{[9]}$.

Based on several studies, the effectiveness of $\beta 2$-agonist is highly different from one patient to another. This study was performed to focus on the relationship between Gln27Glu gene polymorphism of ADRB2 receptor and bronchial asthma susceptibility, severity and response to B2 agonists in Egyptian children.

\section{SUBJECTS AND METHODS}

A case control study was conducted in Pediatric Pulmonology department, on 50 asthmatic children, with age ranges from 5 to 12 years, who were selected and classified into 4 main groups regarding the severity of their illness according to GINA guidelines (2016) into; mild intermittent, mild persistent, moderate persistent and sever persistent asthma. Cases with history of chest infection within the past 2 weeks, short acting B2 agonist intake for less than $12 \mathrm{hs}$ prior to study or complaining of sever concomitant diseases, are discarded from the study. Another 50 healthy non asthmatic group was selected as a control group. Both case and control groups are matched regarding sex characteristic to study its effect.

All cases and control groups underwent detailed history taking, clinical examination and Pulmonary functions evaluation; using (JAEGER MS-IOS digital SPIROMETRY) and an output computer program of (HP Laser Jet Professional P1102). Forced expiratory volume in one second (FEV1), forced vital capacity (FVC) and peak expiratory flow (PEF) parameters were measured. FEV1 was measured in the basal state and 15 minutes after a dose of $0.15 \mathrm{mg} / \mathrm{kg}$ of nebulized Albuterol (short-acting $\beta_{2} \mathrm{AR}$ agonist) was given. To calculate drug response to $\beta_{2} \mathrm{AR}$ agonists, the following formula was used;

\section{Postbronchodilator Prebronchodilator FEV1\% x $100 \%$}

Prebronchodilator FEV1\%

The patient is considered responsive, if the percentage of difference $\geq 15 \%$.

Aseptically collected peripheral blood samples, were taken on EDTA containing tubes for $\mathrm{CBC}$, including peripheral blood eosinophilic percentage, using (CELL-DYN 1700 ,Fisher BioMedical Inc.). Samples also were collected on gel tubes for detection of total serum IgE level by ELISA using; (Biocheck, Inc, CA 94404, USA). Serum is added to the $\operatorname{IgE}$ antibody coated mircotiter wells and incubated with zero buffer at room temperature for 30 minutes. If human $\operatorname{IgE}$ is present in the specimen, it will combine with the antibody on the well ${ }^{[10]}$.

\section{Genotyping}

DNA extraction: Collected samples can be stored at $-20^{\circ} \mathrm{C}$ in $0.5 \mathrm{ml}$ containing EDTA vacutainers till being extracted. DNA extraction was performed following manufacture's protocol of; G-spin ${ }^{\mathrm{TM}}$ Total DNA Extraction Mini Kit produced by; Intron Biotechnology, Korea. Yielded DNA pure samples can be then stored at $-80^{\circ} \mathrm{C}$.

\section{PCR DNA amplification}

For analysis of Gln27Glu site, the following primers were designed; the upstream primer of $\quad \mathrm{Gln} 27$ was 5'GGACCACGACGTCACGCAGC $\quad \mathbf{- 3}$, and that of Glu27 was 5'GGACCACGACGTCACGCAGG -3' and the downstream primer of both was 5'ACAATCCACACCATCAAGAAT -3'.

PCR reactions were carried out by using PCR Master - Mix Gold beads (Bioron, Germany) : $10 \mu \mathrm{l}$ Master mix , $1 \mu 1$ forward primer , $1 \mu 1$ reverse primer , $3 \mu \mathrm{l}$ water and $5 \mu \mathrm{l}$ DNA extract.

The following components were added; DNA template, A pair of primers, four dNTPs (deoxyribonucleotide triphosphates); they are: dATP, dGTP, dCTP, and TTP, Magnesium Chloride $\left(\mathrm{MgCl}_{2}\right)$, Heat stable DNA Polymerase; Taq DNA Polymerase and Buffer solution to stabilize the DNA sample. PCR thermal cycles

Using; (Veriti 96 Well Thermal cycler, Applied Biosystems); the following PCR cycles were done; Initial denaturation at $94{ }^{\circ} \mathrm{C}$ 
for 10 minutes; to separate DNA to 2 single strands. Hybridization of Primers (annealing); at this step, the solution is cooled to around $54^{\circ} \mathrm{C}$. By cooling down the solution, primers are allowed to hybridize with the flanking sequences via hydrogen bonding. DNA Synthesis; Solution heated to $72{ }^{\circ} \mathrm{c}$. At this optimal temperature, the Taq polymerase will start elongates both primers.

Results Interpretation: $10 \mu \mathrm{l}$ of Agarose gel electrophoresis was done using $2 \%$ agarose running gel was performed on 120 volt for 30 minutes and were visualized with ethidium bromide staining.

\section{STATISTICAL ANALYSIS}

Data were coded, entered and analyzed using SPSS version 20 (SPSS Inc, USA). All numeric variables were expressed as mean \pm standard deviation (SD). Allele and genotype frequencies of Gln27/Glu polymorphism were compared using, Chi-square $\left(\chi^{2}\right)$ test which can be used to compare frequency of qualitative variables among different groups and a modified Chi-square Fisher's exact test used for small sample sizes. Odd ratio (OR) and confidence interval (CL 95\%) were also calculated as a measure of association between ADRB2 polymorphism and asthma susceptibility, severity and drug response. For all tests a probability (p) more than 0.05 was considered non-significant, less than 0.05 was considered significant and less than 0.001 was considered highly significant

\section{RESULTS}

There were no statistically significant difference between patients and control regarding age. Both patient and control groups are completely matched regarding sex characteristic to exclude any possible effect of sex variable on the study.

The mean value of BMI was significantly lower among asthmatic patients than control, which was $(19.83+3.21) \quad \mathbf{~ k g} / \mathbf{m}^{2}$ among asthmatic patients, but it was higher in control group by about $3.74 \mathbf{k g} / \mathbf{m}^{2}$, as it was $(23.57+3.83)$.

Risk factors distribution among asthmatic patients in this study were as follows; smoke exposure represented 38\%, URT infection
$72 \%$, Exercise induced asthma 54\%, while family history $54 \%$. So URT infection is considered the main triggering factor in the studied group, followed by exercise induced bronchoconstriction (EIP) and positive family history which represented the same percentage, but smoke exposure was the least common stimulant among studied group. It is clear from these results that, to some extent there is an overlapping or interplay between different risk factors, as some patients have more than one risk factor and others don't have any risk factor at all.

Regarding distribution of asthma severity among patients, mild intermittent asthma was the most frequently distributed class (38\%),followed by Moderate persistent asthma class which was (32\%), then mild persistent asthma (20\%) while the least frequently distributed grade of asthma severity, was the Severe persistent class $(10 \%)$.

There were no statistically significant differences between patients and control regarding Gln27/Glu polymorphism. As Gln27 genotype represents about (36\%) of asthmatic group and (28\%) of control group. Heterozygous Gln27/Glu genotype exerted $(46 \%)$ among patients, while in control group it represents (56\%). Glu27 genotype was found to represent about $18 \%$ and $16 \%$ of patient and control groups respectively (Figure 1).

The spirometeric values of patients were found to be as the following; (1) Basal FEV1\% prior to neubilized B2 agonist administration, ranged between $51.40 \%$ and $94.50 \%$ with a mean of $77.34 \pm 11.96 \%$. (2) FVC\% values ranged between $51.90 \%$ and $113.70 \%$ with a mean of $77.46 \pm 13.41 \%$. (3) PEF\% ranged between $33.90 \%$ and $109.70 \%$ with a mean of $70.63 \pm 15.92 \%$. There was statistically significant difference regarding severity of asthma among patients having Gln27 genotype, $P$ value (0.003). Mild intermittent and persistent asthma grades are combined together and considered as one mild group (table 1). 


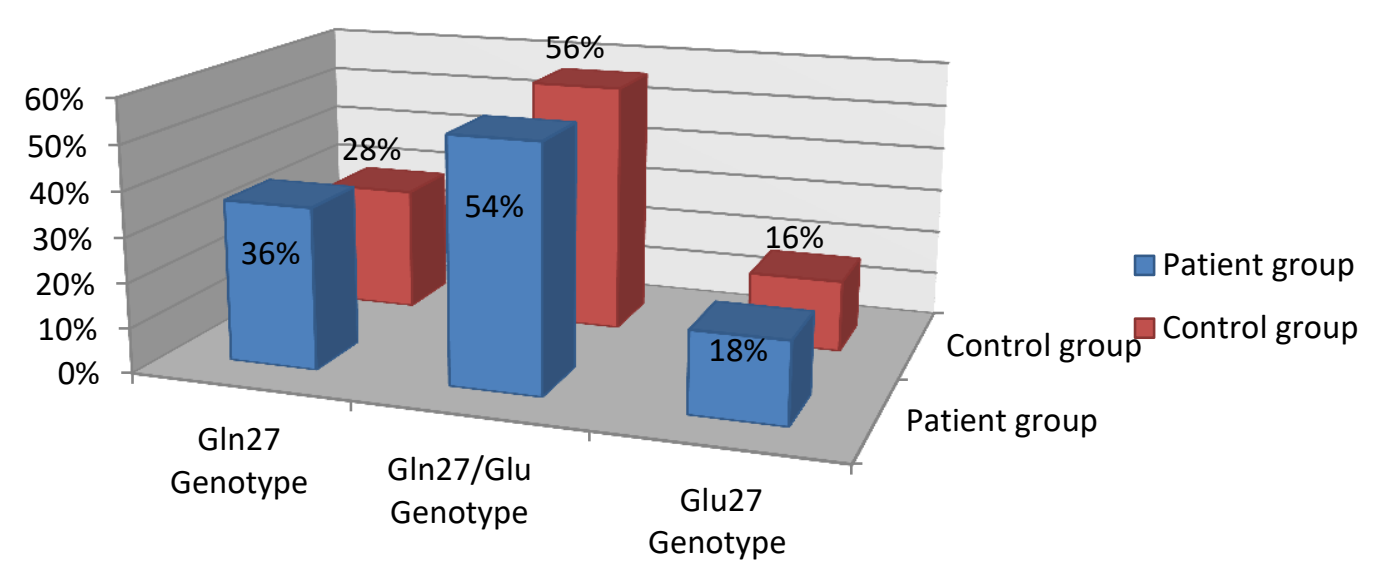

Comparison between patients and control regarding Glu27/Glu Polymorphism.

Figure1:

There was no statistically significant difference between severity of asthma regarding Gln27/Glu Heterozygous, $p$ value (0.072). Also, there was no statistically significant difference between severity of asthma regarding Glu27 homozygous, $\mathrm{p}$ value (0.070).

This study revealed a significant association between Gln27 Homozygous and both hospital admission and Life threatening attacks of asthma, p value is 0.01 for both relations. There was a statistically significant association between Glu27 homozygous and hospital admission for asthma, $\mathrm{p}$ value (0.38). While there was no statistically significant relationship between the same genotype and life threatening attacks of asthma, $p$ value (0.086). There were no statistically significant differences between Gln27/Glu Heterozygous regarding hospital admission and Life threatening attacks, $\mathrm{p}$ value is 0.126 and 0.053 respectively.

\begin{tabular}{lll}
\hline & & \multicolumn{2}{l}{ sample } \\
\cline { 3 - 3 } & & NO. $\%$ \\
\hline \multirow{2}{*}{ Pre neubilized B2 agonist FEV1 \% } & Range & $51.40-94.50$ \\
\cline { 2 - 3 } post neubilized B2 agonist FEV1\% & Mean +SD & $77.34 \pm+11.96$ \\
\hline \multirow{2}{*}{ FVC \% } & Range & $73.30-123.90$ \\
\cline { 2 - 3 } & Mean + SD & $91.82 \pm 9.68$ \\
\hline \multirow{2}{*}{ PEF \% } & Range & $51.90-113.70$ \\
\cline { 2 - 3 } & Mean + SD & $77.46 \pm 13.41$ \\
\hline
\end{tabular}

Table 1: Spirometeric values of patients; FEV1: Forced expiratory volume in 1 second percentage, FVC: Forced vital capacity, PEF: Peak expiratory flow. All measured values are percentages of a normally distributed standard population of the same age group. 


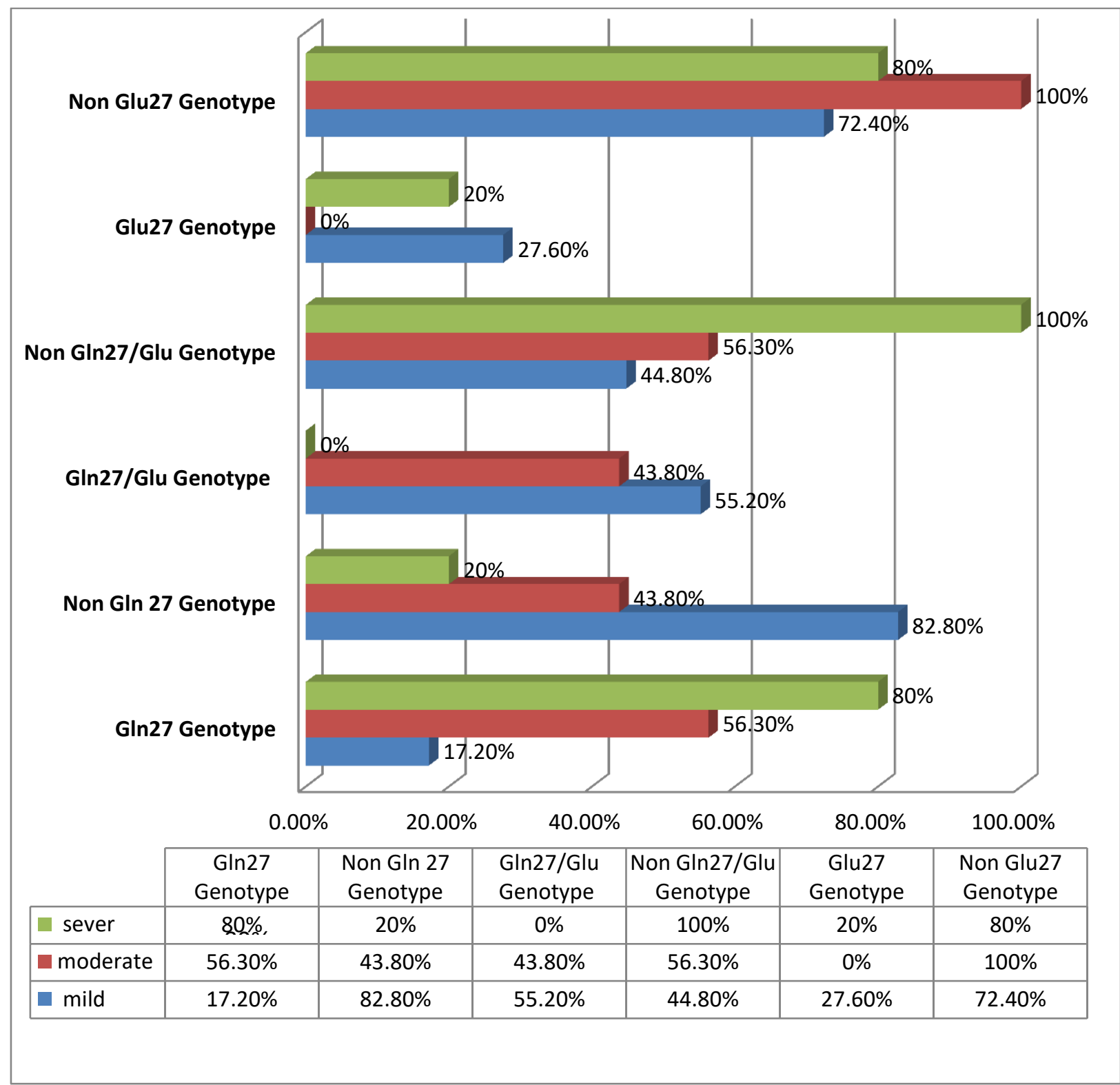

\section{Figure2: Distribution of asthma Severity in relation to each Genotype.}

To evaluate each genotype responsiveness to B2 agonists; FEV1 values before and 15 minutes after administration of a dose of $0.15 \mathrm{mg} / \mathrm{kg}$ albuterol, were measured and compared to calculate the percentage of mean difference. This study has found that, patients having Gln27 genotype are significantly responsive to B2 agonist, as the mean of FEV1 difference between pre and post B2 agonist intake was found to be $19.05 \%$, followed by Gln27/Glu Heterozygous $12.16 \%$, while patients having Glu27 genotype respond poorly to B2 agonist as the mean of difference was $11.23 \%$. 


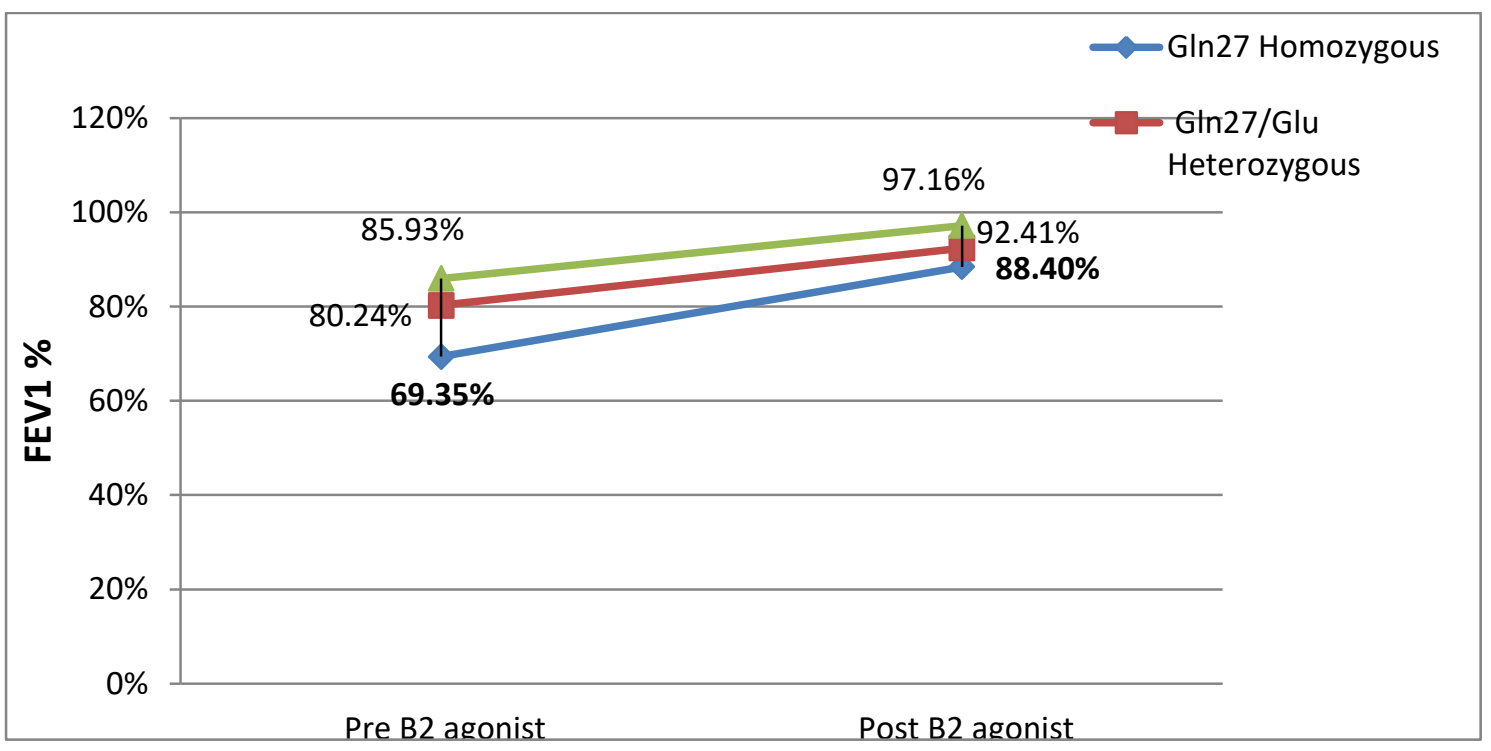

Figure3: Relationship between Gln27 Polymorphism of ADRB2 and drug response. The blue line of Gln27 genotype is more slopped showing more drug response among studied group.

In this study, there were statistically significant difference between mild and moderate asthma regarding total $\mathrm{IgE}$ level $(\mathrm{P}$. value=.002). There were no statistically significant difference between moderate and severe asthma regarding total seum $\operatorname{IgE}$ level $(\mathrm{P}$. value=.761). There were no statistically significant difference between mild and severe asthma regarding Total IgE level (P. value $=.063$ ). Which means that, patients having mild forms of asthma are less liable to have high levels of total serum IgE, while moderate and sever cases not necessarily having high levels of total serum IgE. So we can't rely on total serum IgE level for differentiating between different grades of asthma.

\section{DISCUSSION}

Bronchial asthma is a complex heterogeneous and multifactorial disease, whereas a reversible airway limitation represents one of the main important factors. Asthma is a complex polygenic disorder in which, many cells and cellular elements play a role ${ }^{[1]}$.

WHO declared in December 2016 that, about 235 million people are suffering from asthma.
There are 383000 cases died in 2015 due to asthma.

Asthma has an imp0rtant genetic component but has not shown a clear pattern of inheritance, heritability of asthma vary between 36-79\%. If Phen0type-guided treatment is available for patients with a more severe form of asthma, it will lead to satisfactory results to 


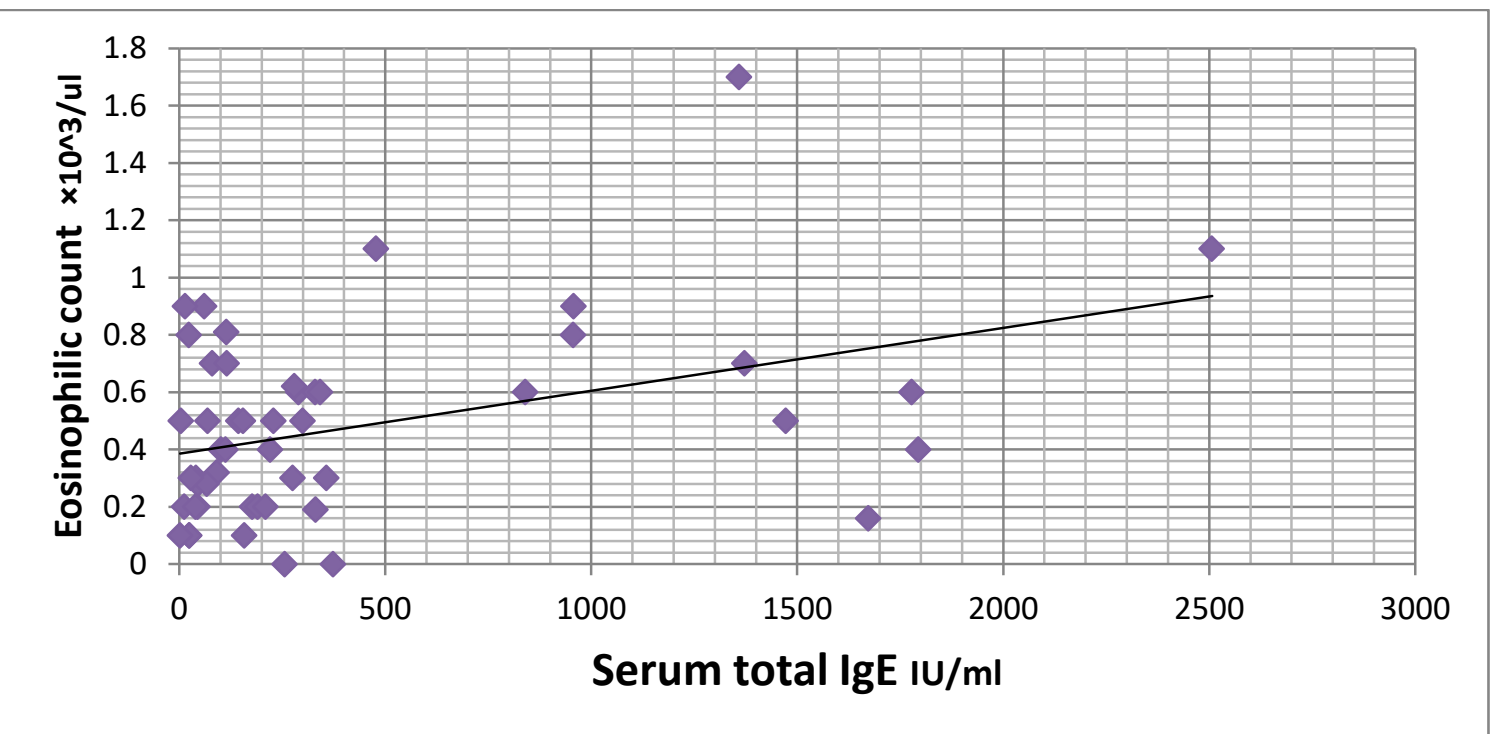

Figure4: Scatter diagram, shows correlation between total serum IgE levels and Eosinophilic counts.

Several single nucleotide polymorphisms (SNPs) in B2 adrenergic receptors have been discovered. Four of these polymorphisms, result in amino acid substitutions at amino acids $16,27,34$, and $164^{[7]}$.

Our study is found to be consistent with Hardy-Weinberg equilibrium; which states that, allele and genotype frequencies will remain constant from generation to generation in absence of other evolutionary influences. These influences include mate choice, mutation, selection, genetic drift, gene flow and meiotic drive.

Our study is found to be compatible with Chinease $^{[12]}$, Indian [13], Japanese ${ }^{[14]}$ and African American [15] studies. But contrasting the Brazilian ${ }^{[16]}$ Canadian ${ }^{[17]}$ and British ${ }^{[18]}$ studies.

An Egyptian study was conducted to investigate the relationship between ADRB polymorphism and nocturnal asthma in children, showed an absence of increased risk for n0cturnal asthma in patients who were Gln/Glu heterozygotes [OR, 1.5; 95\% CI, 0.82.9] and Glu/Glu homozygotes [OR, 1.1; 95\% CI, 0.3-3.5]; there was also an absence of increased risk for the Glu allele [OR, 1.2; 95\% CI, 0.8-2.00] ${ }^{[19]}$.

In a recent Egyptian study published in January $2018^{[20]}$, have confirmed our results and showed that, at amino-acid position 27 of the $\beta 2 \mathrm{AR}$ gene $42.3 \%$ were homozygous for Gln-Gln, $5.8 \%$ were homozygous for Glu-
Glu, and 51.9\% were heter0zygous Gln-Glu. On the other hand, $34.6 \%$ healthy children were homozygous for Gln-Gln, $7.7 \%$ were homozygous for Glu-Glu, and $57.7 \%$ were heterozygous for Gln-Glu.

Another Arabian study having similar ethnic conditions, conducted on population of eastern province of Saudi Arabia, has confirmed also data yielded in our study. Abdullah Al-Rubaish has found that, no statistically significant differences were observed in genotype and allele frequencies between the control and asthmatic groups ${ }_{\beta} 2=0.75, P>.68^{[21]}$.

Regarding the association between severity of asthma and Gln27/Glu polymorphism, this study showed that, the only genotype which was found to have a statistically significant association, was Gln27 genotype, as it represents only $17.2 \%$ of all mild cases, $56.3 \%$ of all moderate cases and about $80.0 \%$ of all sever studied cases; $\mathrm{P}$ value (0.003). On the other hand, the other 2 genotypes combined (Gln27/Glu and Glu27) , represented about $82.8 \%$ of all mild cases, $43.8 \%$ of all moderate cases and about $20.0 \%$ of all sever cases.

Despite of the non-consistent results between our study and the Brazilian one regarding the linkage between asthma susceptibility and Gln27/Glu polymorphism, De paival et al, agree with us, when asthma severity was taken into account. They stated that, 
Gln27Glu polymorphism is a risk factor for severe asthma when the Gln27Gln genotype is present $(\mathrm{OR}=2.798, \mathrm{CI}=1.099$ to 6.674$)$ and a protective factor for mild $(\mathrm{OR}=3.063$, $\mathrm{CI}=1.037$ to 9.041$)$ and severe asthma $(\mathrm{OR}=$ 0.182 , CI $=0.048$ to 0.691 ) when the Gln27Glu genotype is present ${ }^{[22]}$.

Hall et al., 1995, reported also that, the Gln27 allele was associated with greater asthma severity than the Glu27 allele ${ }^{[23]}$. Similarly, the Gln27 polymorphism has been shown to be associated with persistent brOnchial hyperresponsiveness in a random population sample, studied by D'Amato et al., 1998 [24]. In a study of a random English population the Gln27 polymorphism was associated with raised serum IgE levels, although serum $\operatorname{IgE}$ level can't be considered as an indicator of asthma severity ${ }^{[25]}$.

But Holloway et al, 2000, have some contrasting findings to the present study. They observed that, there is no real association between ADRB2 polymorphism and degree of asthma severity. According to this study, the frequency of the Glu27 allele in the both severe and mild asthma groups was not significantly different from that in the control group. Furthermore, the proportion of Glu27 homozyg0tes was similar in the asthma and control groups ${ }^{[26]}$.

However, the Egyptian study of Alghobashy et al, has confirmed the current results, in proving the positive association between polymorphism at codon 27 and asthma severity, it seems to be like an inverted image to ours. They detected that, genotypes GlnGln and Gln-Glu were presented by mild and m0derate asthma, whereas the Glu-Glu genotype was presented by moderate and severe asthma. Where patients with mild intermittent asthma, $38.5 \%$ were homozygous for Glu-Glu and $61.5 \%$ were heterozygous for Gln-Glu ${ }^{[20]}$.

According to the present study, patients carrying Gln/Gln27 genotype can benefit more from using B2 agonists in relieving bronchospasm accompanying bronchial asthma, on contrary with patients carrying other genotypes at codon 27, who respond more weakly to B2 agonists. This strategy is thought to decrease hazards and to reduce expenses of using needless B2 agonists in such non-responding cases.

The results of the current study are consistent with those reported by Tans et al, 1997, who illustrated that, there is significantly greater desensitization to brOnchodilator effect with Glu homozygous than with Gln27 wild genotype $^{[27]}$.

Lee et al 2011, used another bronchodilator rather than Albuterol and suggested that patients with Glu27 may have an increased response to Terbutaline inhalation c0mpared with those with $G \ln 27^{[28]}$.

The Korean study also has confirmed our data, demonstrating that SNPs of ADRB2 have a significant pharmacogenetic association with bronchodilating response to inhaled short-acting B-agonist ${ }^{[29]}$.

Another Indonesian study stated that, ADRB2 polymorphism has no effect on the response to beta-2 agonist; but the Gln-27 polymorphism has with Odds Ratio (OR) $3.18^{[30]}$.

Back to the Egyptian study, there were statistically significant relations between gene polymorphism at codon 27 with both FEV1 and FEV1/FVC ratio. They assumed that, asthmatic heterozygous at codons 27 had a better response to treatment with either bronchodilators only or c0mbined therapy. This study showed that, asthmatic patients with Glu-Glu genotypes do not respond to bronchodilator alone but to bronchodilator and ICS ${ }^{[20]}$. In addition, De Paiva et al. found that asthmatic subjects homozygous for Glu 27 have less airway responsiveness than asthmatic homozygous for Gln $27^{[22]}$.

According to our study, no significant relationship had been found between Gln27/Glu polymorphism of B2 adrenergic receptor and elevated levels of neither total serum IgE nor eosinophilic count for all studied genotypes.

Giubergia et al, detected also, no significant difference of the total serum IgE level at position 27; moreover, when population was stratified according to the most common homozygous haplotype no association was found in relation to serum $\operatorname{IgE}{ }^{[31]}$.

In this context, our study has several strengths and limitations: our sample size may be considered small; there is no control for 
envir0nmental factors; only one SNP was analyzed; the Egyptian population is to some extent, admixed; and a region with a specific genotype combination associated with risk may also be associated with a peculiar environmental factor.

Diseases with a complex genetic origin, such as asthma, also may be characterized by plei0tropy (the same genotype has different phenotypes), genetic heterogeneity (the same phenotype results from different polymorphisms), and incomplete penetrance (the same polymorphism does not always produce the same phenotype ${ }^{[32]}$.

\section{CONCLUSION}

B2 adrenergic receptor polymorphism at codon 27 is not associated with asthma susceptibility; however it can be a determinant factor for asthma severity and bronchodilating response to B2 agonists in Egyptian asthmatic children, to be confirmed by further Pharmacogenomic studies.

\section{REFERENCES}

1- Ober C. and Hoffjan S.: Asthma genetics 2006: the long and winding road to gene discovery. Genes Immun; 2006; 7:95-100.

2- WHO "World Health Organization" Fact sheet: Asthma No: 307; ; 2016; updated April 2017;

http://www.who.int/mediacentre/factsheets/fs3 07/en/.

3- Alameldin M., Sanusy K.A., Said W.S., Mahran D.G. and Hussein A.M.:Epidemiology of bronchial asthma among preparatory school children in Assiut district. Egypt J. Pediatr Allergy Immunol.; 2012;10(2):109-117.

4- Abd Elmoneim A., Hassan I., Abd Elnaby A. and Abou Elmagd A.: Epidemiology and medical centre. outcome of childhood asthma: a clinical study in an Egyptian university East Mediterr Health J.; 2013; 19(6):520-526.

5- Lee Y.L., Wang S.T., Tsai C.H. and Guo Y. L: Associations of B2-Adrenergic Receptor genotypes and haplotypes with wheezing illness in Taiwanese schoolchildren. Allergy; 2009; 64: 1451-7.

6- Maxwell T.J., Ameyaw M.M., Pritchard S., Thornton N., Folayan G. and Githang'a J.,: Beta-2 adrenergic receptor genotypes and haplotypes in different ethnic groups. Int J Mol Med; 2005; 16(4): 573-580.

7- Kume H., Hall I.P., Washabau R.J. Takagi k., and Kotlikoff M. I. : Beta-adrenergic agonists regulate $\mathrm{KCa}$ channels in airway smooth muscle by cAMP dependent and independent mechanisms. J Clin Invest.1994; 93(1):371-379.

8- Moore P.E., Laporte J.D., Abraham J.H., Schwartzman I.N., Yandava C.N., Silverman E.S. et al.: Polymorphism of the beta (2)-adrenergic receptor gene and desensitization in human airway smooth muscle. Am J Respir Crit Care Med; 2000 162(6):2117-2124.

9- Weiss S.T. : New approaches to personalized medicine for asthma: Where are we? The Journal of Allergy and Clinical Immunology;2012; 129(2): 327-334.

10- Lequin R.M.: "Enzyme Immunoassay (EIA)/Enzyme-Linked Immunosorbent Assay (ELISA)". Clinical Chemistry;2005; 51 (12): 2415-8.

11- Isi H, Oral D, Yildiz T, Ates G and Sinir C, Ay O.I., Turkoz G. and Erdal M.E.: The Tumor necrosis factor-a -308 G/A Polymorphism and tumor necrosis factor related apoptosis -inducing ligand polymorphisms, in asthmatic patients and healthy subjects .Biotechnol. \& Biotechnol;2010; 24(1): 1638-1643.

12- Wei-ping FU., Zhi-Huan Zhao, Li Zhong, Chang Sun, Li-Zhou Fang and Ling Liu,: Relationship between polymorphisms in the 5 leader cistron, positions 16 and 27 of the adrenergic b2 receptor gene and asthma in a Han population from southwest Chinaresp_2028 Asian Pacific Society of Respirology; 2011; 16, 1221-1227.

13- Bhatnagar P., Gupta S. and Guleria R.: Beta2-Adrenergic receptor polymorphisms and asthma in the North Indian population. Pharmacogenomics 2005; 6: 713-19.

14- Migita O., Noguchi E., Jian Z., Shibasaki M., Ichikawa K., Matsui A. and Arinami T.: ADRB2 polymorphisms and asthma susceptibility: transmission disequilibrium test and meta-analysis. Int. Arch. Allergy Immunol. 2004; 134: 150-7.

15- Summerhill E., Leavitt S.A. and Gidley H: Beta(2)-adrenergic receptor Arg16/Arg16 genotype is associated with reduced lung function, but not with asthma, in the Hutterites. Am. J. Respir. Crit. Care Med. 2000; 162: 599-602.

16- Woszczek G., Borowiec M., Ptasinska A., Kosinski S., Pawliczak R. and Kowalski M.L.:Beta2-ADR haplotypes/polymorphisms associate with bronchodilator response and 
total IgE in grass allergy. Allergy 2005, 60(11):1412-1417.

17- Matheson M.C., Ellis J.A., Raven J., Johns D.P., Walters E.H. and Abramson M.J.: Beta2-adrenergic receptor polymorphisms are associated with asthma and COPD in adults. J. Hum. Genet. 2006; 51: 943-51.

18- Hall I.P., Blakey J.D., Al Balushi K.A., Wheatley A., IanSayers and Epembrey M.: Beta2-adrenoceptor polymorphisms and asthma from childhood to middle age in the British 1958 birth cohort: a genetic association study. Lancet 2006; 368: 771-9.

19- Karam R.A., Sabbah N.A., Zidan H.E. and Rahman H.M.A.: Association between Genetic Polymorphisms of B2 Adrenergic Receptors and Nocturnal Asthma in Egyptian children. J Investig Allergol Clin Immunol 2013; 23(4): 262-266.

20- AlghobashyA.A., Elsharawy S.A, Alkholy1 U.M, Abdalmonem N., Abdou M.A. and Basset M.A.: B2 adrenergic receptor gene polymorphism effect on childhood asthma severity and response to treatment. International Ped res; 2017 doi:10.1038/pr.2017.304.

21- Al-Rubaish A.M. :Association of Beta 2adrenergic receptor gene polymorphisms and nocturnal asthma in Saudi patients. Annals of Thoracic Medicine. 2011; 6(2):66-69.

22- De Paiva A.C.Z., De Lima Marson F.A., Ribeiro J.D. and Bertuzzo C.S.: Asthma: Gln27Glu and Arg16Gly polymorphisms of the beta2-adrenergic receptor gene as risk factors Asthma \& Clinical Immunology 2014, $10: 8$

http://www.aacijournal.com/content/10/1/8.

23- Hall I.P., Wheatley A., Wilding P. and Liggett S.B: Association of Glu 27 beta 2adrenoceptor polymorphism with lower airway reactivity in asthmatic subjects. Lancet 1995; 345:1213 \pm 4 .

24- D'Amato M., Vitiani L.R., Petrelli G, Ferrigno L., di Pietro A. and Matricardi P.M.: Association of persistent bronchial hyperresponsiveness with b2-Adrenoceptor (ADRB2) Haplotypes: a population study. Am J Respir Crit Care Med 1998; 158:1968_73.
25- Dewar J.C., Wilkinson J.,Wheatley A., Thomas N.S., Doulle I. and Morton N.: The glutamine 27 b2-adrenoceptor polymorphism is associated with elevated IgE levels in asthmatic families. J Allergy Clin Immunol 1997; 100:261 \pm 5 .

26- Holloway J.W., Dunbar P.R., Riley G.A., Sawyer, Fitzharris, Pearce and Le Gros: Association of b2 adrenergic receptor polymorphisms with severe asthma. Clin Exp Allergy 2000;30: 1097 \pm 103 .

27- Tans S., Hall I.P., Dewar J., Dow E. and Lipworth B. :Association between b2 adrenoreceptor polymorphisms and susceptibility to bronchodilator desensitization in moderately severe stable asthmatics. Lancet 1997; 350:995 \pm 9 .

28- Lee M.Y., Cheng S.N., Chen S.J., Huang H.L., Wang C.C. and Fan H.C.: Polymorphisms of the 32 -adrenergic receptor correlated to nocturnal asthma and the response of terbutaline nebulizer. Pediatrics and Neonatology. 2011;52(1):18-23.

29- Cho S.H., Ohwz S.Y., Bahn J.W., Choiw J.U., Chang Y.S and Kim Y.K.: Association between bronchodilating response to shortacting b-agonist and non-synonymous singlenucleotide polymorphisms of b2-adrenoceptor gene Clin Exp Allergy 2005; 35:1162-1167 doi:10.1111/j.1365-2222.2005.02319.

30- Syamsu, Irawan Yusuf, Budu, Ilhamjaya and Patellongi: The Effect of Polymorphysm of The $\beta-2$ Adrenergic Receptor on The Response to $\beta-2$ Agonist in Bronchial Asthma Patients Acta Med Indones-Indones J Intern Med; 2007;39,1.

31- Giubergia V., Zelazko M., Roy A., Gravina L.P., Gonzalez Pena H. and Chertkoff L.: $\beta 2$-adrenergic polymorphisms and total serum IgE levels in children with asthma from Argentina. Ann Allergy Asthma Immunol 2009; 102:308-13.

32- Michael B.B., Kathleen B., Elizabeth T. and David C.C.: (2002): Genetic and Perinatal Risk Factors for Asthma Onset and Severity: A Review and Theoretical Analysis Epidemiologic Reviews; 24:176-189. 